\title{
THE IMPACT OF OVERCONFIDENCE BIAS ON PERSONAL INVESTMENT DECISIONS: THE CASE OF NORTH MACEDONIA
}

\author{
Shenaj Hadzimustafa \\ Faculty of Business and Economics - Tetovo \\ s.daut@seeu.edu.mk \\ Nermine Shabani \\ High School "Saraj" - Skopje \\ ns21947@seeu.edu.mk
}

\begin{abstract}
The "Financial Behavior" in the field of "decision making" is the topic that awarded the economist Richard H. Thaler the Nobel Prize in 2017. According to him, after many investigations made on human decisions, it is noticed that they often depend on nature, intuition, habits, cognitive biases, emotional biases which lead the investor to wrong decisions. Given that the investments play an important and central role in the economy, the main purpose of the paper is to analyze the investment decision making process based on emotional bias, or more specifically the overconfidence bias. This study captures the impact of gender, and level of education on overconfidence during investment decision making in North Macedonia. The results show that investors' decisions were significantly influenced by the overconfidence bias. Although men and women are found to be overconfident, studies have shown that the degree of overconfidence varies among them and men are more overconfident than women. Also, overconfidence increases with the level of education.

Based on the results certain recommendations are provided in order to assist future investment decision-making processes by notifying and eliminating the overconfidence bias identified during this research as a key factor leading to wrong and failing, non-rational investment decision making.
\end{abstract}

Keywords: Behavioral Finance, Biases, Investment Decision, Investors, Overconfidence.

JEL classification: $G 02, G 00, G 11$.

\section{INTRODUCTION}

Investors are influenced by many factors. The main hypothesis in this research is that the overconfidence bias affects investors decisions. Overconfidence bias is one of the many biases that behavioral finance identifies. Based on the complexity of the individual's character, it is very important for investors to have knowledge of these types of biases that affect the timing of investment decisions. We are unlikely to eliminate bias, but if we are aware of its existence and effect, we will be able to avoid the main pitfalls.

Kahneman and Riepe (1998) stated that it is very important to understand the investment decision making processes as they have both financial and emotional consequences overtime. Investors use several heuristics and exhibit behavioral biases during the process of making investment decisions.

The word "Bias" has been defined as "tendency towards a certain disposition or conclusion" (Wolman, 1973, p. 44). Sahi and Arora (2012) stated that the literature of behavioral finance considers bias as a systematic deviation from the norm, or an inclination for a particular 
judgment. Kahneman and Twersky (1974) brought into light how investors take decisions under uncertainty, the causes and effects of human error. Kahneman and Riepe (1998) introduced behavioral biases in three categories (1) biases of judgment, (2) errors of preference, and (3) biases associated with living with the consequences of decisions. Biases of judgment include overconfidence, optimism, hindsight, and overreaction to chance events.

The decision-making process of investors includes a quantitative (objective) and qualitative (subjective) aspect based on the characteristics of the investment product or financial service. Investor behavior examines the mental processes and emotional biases that individuals, financial experts, and traders discover during the process of financial planning and investment management.

Emotional biases come from feelings, intuition, or impulsive thinking, and these types of biases can lead to weak, erroneous, irrational investment decisions. This is why understanding different biases and behavioral traits can help an individual make sound financial decisions, which is the key to successful investment (Ricciardi and Simon, 2008).

As a fundamental part of human nature, these biases affect all types of investors, both professional and private (Byrne and Utkus, 2013). They can also affect all types of decisionmaking, but they have special implications for investment and money. So since it is natural for us, the only thing we can do is be aware of their existence and try to manage and control them, since, when you are aware of the existence of a problem, you are able to deal with it in the most efficient way.

The analysis in the paper is followed by literature review, methodology and interpretation of the results. At the end conclusion and recommendations are given.

\section{LITERATURE REVIEW}

The psychological fact known as bias and its presence in human decision making provide the additional insight on the subject of investor irrationality and broaden the ideals of rationality (Chira, Adams and Thornton, 2008). Shefrin, has defined bias as being nothing more than the "predisposition towards error" (Shefrin, 2007). Shefrin (2007) defines bias as a predisposition towards error: It is a prejudice or a propensity to make decisions while already being influenced by an underlying belief.

Behavioral aspects and aims on application of psychological and economic principles for the improvement of individual financial decision making process are being acquainted by Behavioral Finance. Shefrin (2000) has written in his book named as "Beyond Greed and Fear" which is based on behavioral finance and EMH that people are "imperfect processors" of information and are usually biased, mistakes are being consigned and perceived by the people. In the present era, no unified theory of behavioral finance exists.

Decision making is being affected by overconfidence bias, in the corporate world as well as individual investments. Shefrin defines overconfidence as "showing concern about knowing one's own abilities and boundaries of knowledge" (Shefrin, 2007).

Studies emphasize that individuals are affected by psychological factors such as cognitive biases in their decision making process, rather than being rational and wealth-maximizing (Forbes, 2009).

Overconfidence has been studied in perplexingly different ways. De Bondt and Thaler (1985) argued that "the key behavioral factor needed to understand the trading puzzle is overconfidence".

Investors are full of overconfidence which can be defined as ignoring the apparent reasoning and having inopportune beliefs, judgments, and person's capabilities (Sadi, Ghalibaf, Rostami, and Gholipour, 2011). 
According to Gervais and Odean (2001), the level of overconfidence decreases as an investor becomes more experienced.

The experiments by Gloede and Menkhoff (2011) show that working experience of a professional is accompanied by less overconfidence.

The danger of an overconfidence bias is that it makes one prone to making mistakes in investing. Overconfidence tends to make us less than appropriately cautious in our investment decisions. Many of these mistakes stem from an illusion of knowledge and/or an illusion of control. Experimentally alerting overconfident investors can eliminate overconfidence (Bloomfield et al. 1999). Likewise, Zacharakis and Shepherd (1999) recommend to reduce overconfidence by improving knowledge and thereby the decision quality of venture capitalists.

\section{METHODOLOGY}

\subsection{Sample and data collection}

The purpose of this study is to verify the impact of overconfidence bias on investment decisions. In order to achieve the purpose of the study, a structured questionnaire was designed to collect the data for further statistical tests. 450 questionnaires were distributed, out of which 110 were received back. The distribution of questionnaires was through physical and electronic methods. The deductive method was the main method used for analyzing the data.

\subsection{Demographic detail of the respondents:}

The total response sample size was 110 questionnaires, 72 male respondents $(65.6 \%$ of total sample size) and 38 female respondents which equals $34.5 \%$.

The population was categorized in six age groups as follows: less than 20 years; 21-30 years; 31-40 years; $41-50$ years; 51-60 years and more than 60 years.

The age group of 31-40 years consists the largest share in the analyzed population with a total of $40 \%$ or 44 respondents. Then the age group from $21-30$ years with a total of $39.1 \%$ or 39 respondents; followed by the age group from $41-50$ years with a total of $15.5 \%$ or 17 respondents; whereas the individual investors that belong to the "less than 20 years" and "more than 60 years" age group include the smallest share of investors with $0.9 \%$ or 1 respondent and $3.6 \%$ or 4 respondents, respectively.

The results obtained from the survey show that the highest percentage of respondents are citizens of the city of Skopje with a total of $53.6 \%$ or 59 respondents; followed by the city of Tetovo with $22.7 \%$ or 25 respondents; and the city of Gostivar with $13.6 \%$ or 15 respondents. The results collected from the survey show that the dominant part of the respondents are the respondents with University Education with a total of $53.2 \%$ or 58 respondents; followed by Middle School respondents with a total of $24.8 \%$ or 27 respondents and then respondents with Post-University Studies with a total of $14.7 \%$ or 16 respondents. The lowest percentage is represented by the respondents with primary school with a total of $0.9 \%$ or 1 respondent. In the analyzed poll $72.7 \%$ or 80 respondents are with "married" status, while the respondents with "single" status include $27.3 \%$ or 30 respondents.

\subsection{Questionnaires and scale}

The questionnaire consists of 6 categories of questions that focus on different aspects that affect the investment decision. The group of questions that analyze the impact of the overconfidence 
on the investment decisions given in the null hypothesis consists from four questions which will be given in the following part.

Each descriptive question in the questionnaire was presented with three descriptive options: "always", "sometimes" and "never".

\section{DATA ANALYSIS AND INTERPRETATION}

The aim of the study was to verify the impact of overconfidence bias on personal investment decision-making of individual investors in the Republic of North Macedonia. In this part of the research the collected data along with the results are presented, interpreted and analyzed. In order to test the hypothesis of this research a questionnaire was distributed and 110 responses were used for the data analysis. The results are summarized and presented in tabular and graphic forms.

The hypothesis put the following states forward:

H0: Overconfidence bias affects personal investment decisions

Table 1. Even if the investment may have a high risk, I still don't guess because I believe in my infallible decisions, gender and age structure

\begin{tabular}{|c|c|c|c|c|}
\hline Gender / Age & Always & Sometimes & Never & Total \\
\hline Female & $17.27 \%$ & $13.64 \%$ & $3.64 \%$ & $34.55 \%$ \\
\hline 20-30 years & $10.00 \%$ & $9.09 \%$ & $3.64 \%$ & $22.73 \%$ \\
\hline $31-40$ years & $7.27 \%$ & $4.55 \%$ & $0.00 \%$ & $11.82 \%$ \\
\hline Male & $36.36 \%$ & $26.36 \%$ & $2.73 \%$ & $65.45 \%$ \\
\hline less than 20 years & $0.91 \%$ & $0.00 \%$ & $0.00 \%$ & $0.91 \%$ \\
\hline 20-30 years & $9.09 \%$ & $6.36 \%$ & $0.91 \%$ & $16.36 \%$ \\
\hline $31-40$ years & $18.18 \%$ & $10.00 \%$ & $0.00 \%$ & $28.18 \%$ \\
\hline $40-50$ years & $6.36 \%$ & $9.09 \%$ & $0.00 \%$ & $15.45 \%$ \\
\hline 51-60 years & $1.82 \%$ & $0.91 \%$ & $0.91 \%$ & $3.64 \%$ \\
\hline more than 60 years & $0.00 \%$ & $0.00 \%$ & $0.91 \%$ & $0.91 \%$ \\
\hline Total & $53.64 \%$ & $40.00 \%$ & $6.36 \%$ & $100.00 \%$ \\
\hline
\end{tabular}

The results in Table 1 show that even if the investment may have a high risk, still $53.64 \%$ of the investors, or more specifically $17.27 \%$ females and $36.36 \%$ males believe in their infallible decisions The structure of the investors in the research poll is as follows: $65.45 \%$ consisting of male investors and $34.55 \%$ consisting of female investors. The overconfidence, given with the belief in the infallible decisions is always present in the female aging group from 21-30 years, with $10 \%$ out of the total sample and $18.18 \%$ in the male age group from $31-40$ years. $40 \%$ of the respondents sometimes believe in their infallible high risk investment decisions.

Table 2. Even if the investment may have a high risk, I still don't guess because I believe in my infallible decisions, gender and educational structure

\begin{tabular}{|c|c|c|c|c|}
\hline Gender/Education & Always & Sometimes & Never & Total \\
\hline Female & $17.27 \%$ & $13.64 \%$ & $3.64 \%$ & $34.55 \%$ \\
\hline High school & $0.91 \%$ & $0.00 \%$ & $0.00 \%$ & $0.91 \%$ \\
\hline University education & $10.00 \%$ & $12.73 \%$ & $2.73 \%$ & $25.45 \%$ \\
\hline Post-University education & $6.36 \%$ & $0.91 \%$ & $0.91 \%$ & $8.18 \%$ \\
\hline
\end{tabular}




\begin{tabular}{|l|r|r|r|r|}
\hline Male & $\mathbf{3 6 . 3 6 \%}$ & $\mathbf{2 6 . 3 6 \%}$ & $\mathbf{2 . 7 3 \%}$ & $\mathbf{6 5 . 4 5 \%}$ \\
\hline Primary education & $0.00 \%$ & $0.91 \%$ & $0.00 \%$ & $0.91 \%$ \\
\hline High school & $14.55 \%$ & $9.09 \%$ & $0.91 \%$ & $24.55 \%$ \\
\hline University education & $18.18 \%$ & $11.82 \%$ & $0.00 \%$ & $30.00 \%$ \\
\hline Post-University education & $3.64 \%$ & $4.55 \%$ & $1.82 \%$ & $10.00 \%$ \\
\hline Total & $\mathbf{5 3 . 6 4 \%}$ & $\mathbf{4 0 . 0 0 \%}$ & $\mathbf{6 . 3 6 \%}$ & $\mathbf{1 0 0 . 0 0 \%}$ \\
\hline
\end{tabular}

According to Table 2. focusing on the impact of overconfidence bias on personal investment decisions seen through the education and gender prism, we can conclude that the assertion of overconfidence bias in investment decision making is always and sometimes at women with university education with $22.73 \%$ of total respondents. The statement of overconfidence bias in investment decision-making at men with high school and university education is always and sometimes present by round $55 \%$ of the respondents.

Table 3. My skills and knowledge of investment forms help me in the investment decisionmaking process, age distribution

\begin{tabular}{|l|r|r|r|}
\hline \multicolumn{5}{|l|}{ Age } & Always & Sometimes & $\begin{array}{l}\text { Grand } \\
\text { Total }\end{array}$ \\
\hline less than 20 years & $0.91 \%$ & $0.00 \%$ & $0.91 \%$ \\
\hline $20-30$ years & $23.64 \%$ & $15.45 \%$ & $39.09 \%$ \\
\hline $31-40$ years & $24.55 \%$ & $15.45 \%$ & $40.00 \%$ \\
\hline $41-50$ years & $12.73 \%$ & $2.73 \%$ & $15.45 \%$ \\
\hline $51-60$ years & $2.73 \%$ & $0.91 \%$ & $3.64 \%$ \\
\hline more than 60 years & $0.91 \%$ & $0.00 \%$ & $0.91 \%$ \\
\hline Grand Total & $\mathbf{6 5 . 4 5 \%}$ & $\mathbf{3 4 . 5 5 \%}$ & $\mathbf{1 0 0 . 0 0 \%}$ \\
\hline
\end{tabular}

The results in Table 3 show that $65.45 \%$ of the analyzed respondents agree that their skills and knowledge of the investments forms are enough for the investment decision making process they are making, where seen through the age distribution this overconfidence bias is the highest in the 20-40 years group which consists almost half of the population that is being analyzed. 
Figure 1. My skills and knowledge of investment forms help me in the investment decisionmaking process, regional distribution

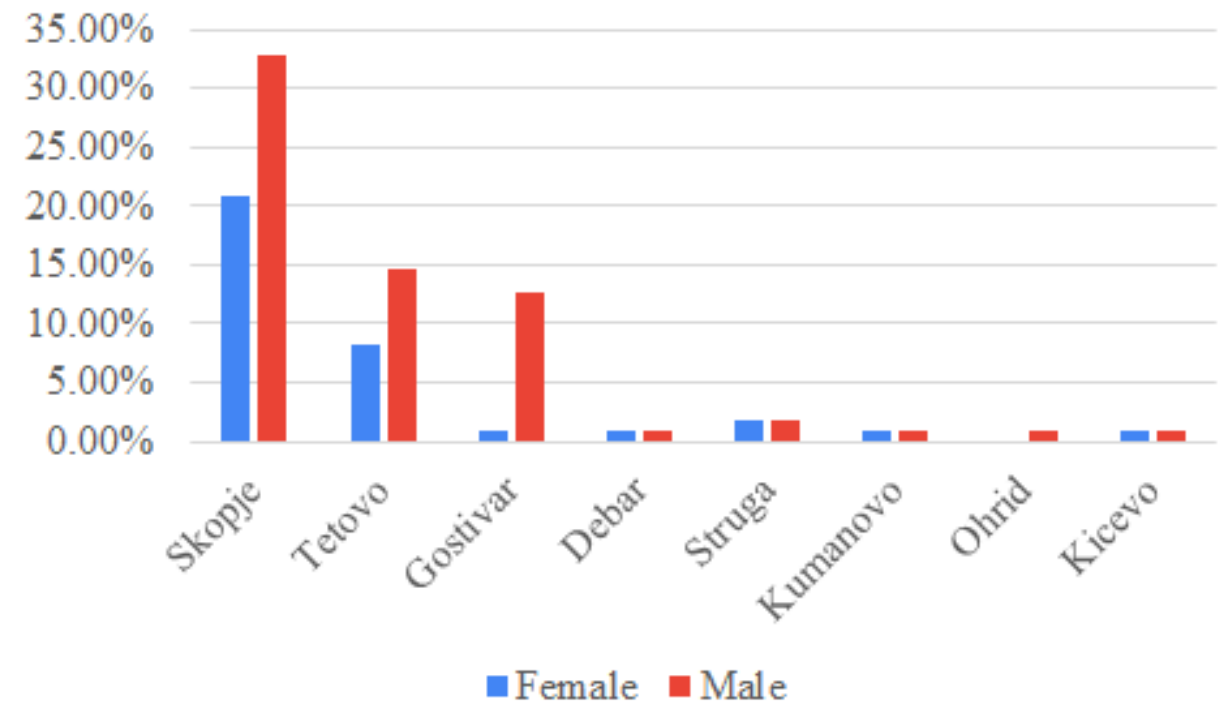

Seen from regional perspective (given in Figure 1) the self-confidence bias is present with more that $30 \%$ of male from the total male analyzed in the poll in the city of Skopje, followed by male in Tetovo and Gostivar. Around $30 \%$ of the biased females come from Skopje and Tetovo.

Figure2. My skills and knowledge of investment forms help me in the investment decisionmaking process, gender distribution

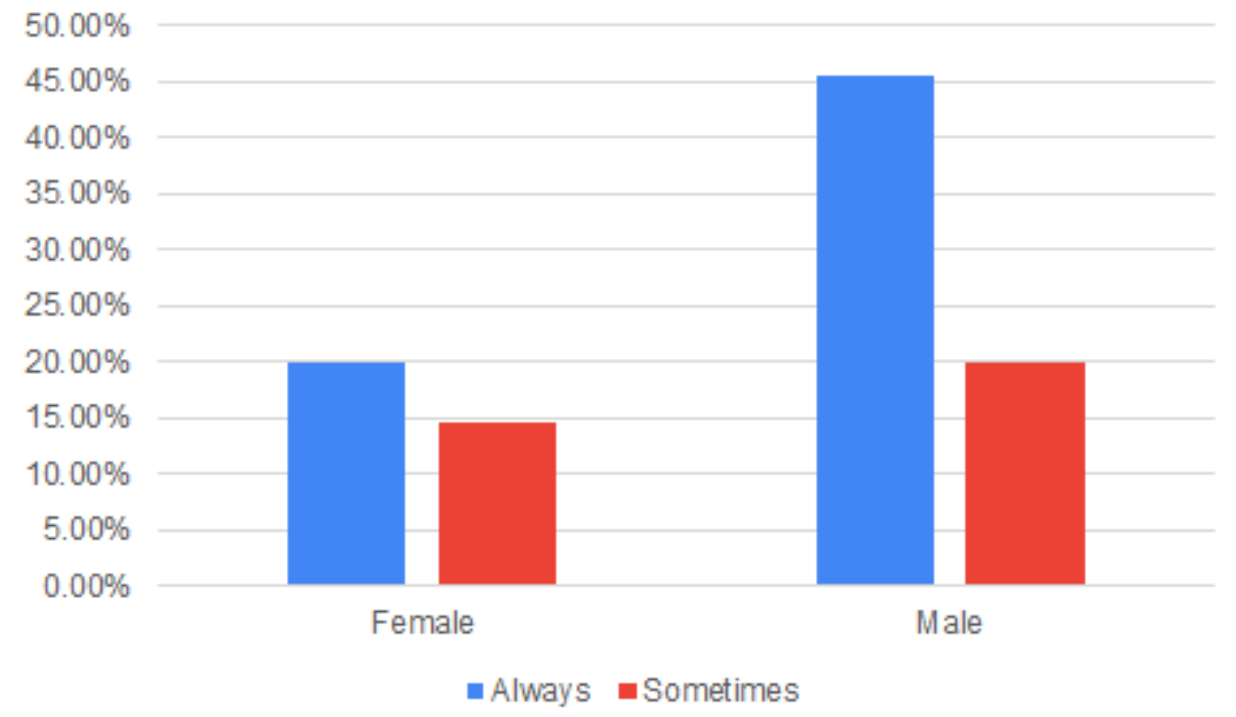

Analyzed from gender perspective, what is evident is that male are more biased than females in their investment decisions, where $45 \%$ of male always base their investment decisions on their skills and knowledge, compared to $20 \%$ of females. 
Table 4. My investment decisions will definitely bring a high return, age distribution

\begin{tabular}{|l|r|r|r|r|}
\hline Age & Always & Sometimes & Never & \multicolumn{1}{l|}{$\begin{array}{l}\text { Grand } \\
\text { Total }\end{array}$} \\
\hline less than 20 years & $0.91 \%$ & $0.00 \%$ & $0.00 \%$ & $0.91 \%$ \\
\hline $20-30$ years & $20.00 \%$ & $16.36 \%$ & $1.82 \%$ & $39.09 \%$ \\
\hline $31-40$ years & $26.36 \%$ & $13.64 \%$ & $0.00 \%$ & $40.00 \%$ \\
\hline $41-50$ years & $11.82 \%$ & $3.64 \%$ & $0.00 \%$ & $15.45 \%$ \\
\hline $51-60$ years & $2.73 \%$ & $0.91 \%$ & $0.00 \%$ & $3.64 \%$ \\
\hline more than 60 years & $0.00 \%$ & $0.91 \%$ & $0.00 \%$ & $0.91 \%$ \\
\hline Grand Total & $\mathbf{6 1 . 8 2 \%}$ & $\mathbf{3 5 . 4 5 \%}$ & $\mathbf{1 . 8 2 \%}$ & $\mathbf{1 0 0 . 0 0 \%}$ \\
\hline
\end{tabular}

Table 4 shows that $61.82 \%$ of the respondents that have undertaken a certain investment decision believe that it will bring them a high return on investment, out of which $26.36 \%$ belong to the 31-40 years aging group. On the other hand, $16.36 \%$ of the respondents that believe that their investments can bring them sometimes a high return belong to the 20-30 years aging group.

Figure 3. My investment decisions will definitely bring a high return, gender and education distribution

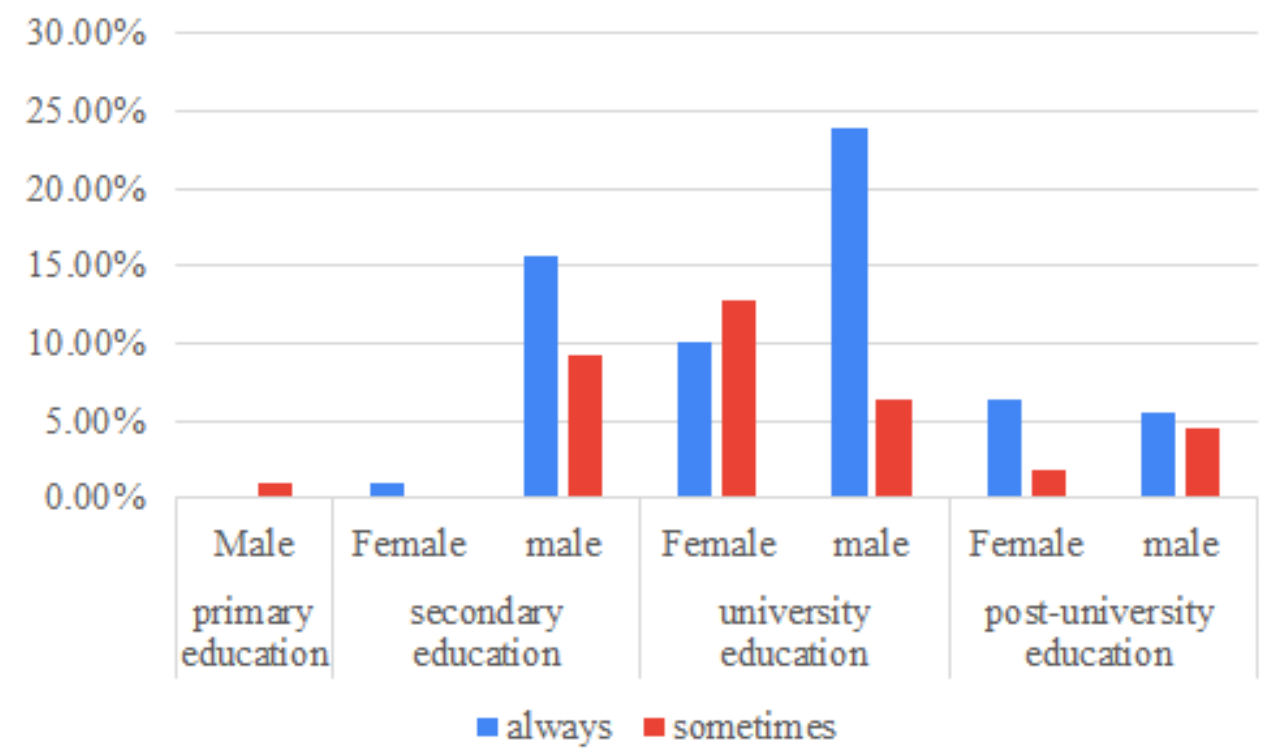

Males are more optimistic than females towards their investments return in the future, which could be seen from Figure 3, whereas around $65 \%$ of the respondents that believe in high return of their investments are male and the rest are females. Analyzed through educational attainment, the investment returns are expected to be higher at male with secondary and university education, whereas females with higher education sometimes expect that their investments will bring higher returns which is mostly dominant in the female group with university education with $13 \%$ of the total respondents.

Given the results from the respondents' answers we can conclude that the null hypothesis is being accepted. 


\section{CONCLUSION AND RECOMMENDATIONS}

As Shefrin (2000) points out, investors need to recognize their mistakes and those of others, understand those mistakes, and take steps to avoid them.

The purpose of this research was to shed light on the phenomenon of overconfidence bias on investment decision making in real and financial assets.

The research paper summarizes the answers to the research question raised at the beginning of the research, which means that the research objectives have been achieved and the hypothesis has been tested. On this basis, we conclude that investors' personal investment decisions were largely influenced by emotional bias, "overconfidence", a factor that influenced the wrong decision-making of investors. Investors thus showed that their decisions are influenced by overconfidence bias attitudes toward being rational. The answers given by majority of the respondents verify the null hypothesis which stated that the overconfidence bias affects the investment decision.

A recommendation that could be given to the individual investors is their better understanding of the psychology and emotions underlying investment decisions that can help both financial advisors and individual investors in formulating their financial goals better.

Future research should further investigate overconfidence on the relation between overconfidence and personality traits, such as attribution styles, is needed to learn when and why certain characteristics trigger overconfidence.

\section{REFERENCES}

Bloomfield, R., and O'Hara, M. (1999), "Market Transparency: Who Wins and Who Loses?", The Review of Financial Studies, Vol. 12 No. 1, pp. 5-35.

Byrne, B.A., and Utkus, W.S.P. (2013), "Understanding How the Mind Can Help or Hinder Investment Success", VAM, pp. 05-08.

Chira, I., Adams, M., and Thornton, B. (2008), "Behavioral Bias Within the Decision Making Process", Journal of Business \& Economics Research (JBER), Vol. 6 No. 8, pp. 11-20.

De Bondt W. and Thaler, R. (1985), "Does the Stock Market Overreact?", The Journal of Finance, Vol. 40, No. 3, pp. 793-805.

Forbes, W. (2009), Behavioral Finance, John Wiley \& Sons Ltd, Chichester, UK.

Gervais, S. and Odean, T. (2001), "Learning to be overconfident", Review of Financial Studies, Vol. 14 No. 1, pp. 1-27.

Gloede, O., Menkhoff, L. and Waibel, H. (2011), "Risk Attitude and Risk Behavior: Comparing Thailand and Vietnam", Proceedings of the German Development Economics Conference, Berlin 2011, No. 33, Verein für Socialpolitik, Research Committee Development Economics.

Kahneman, D. and Twersky, A. (1974), "Judgment under Uncertainty: Heuristics and Biases", Science, Vol. 185, No. 4157, pp. 1124-1131.

Kahneman, D. and Riepe, M.W. (1998), “Aspects of Investor Psychology”, Journal of Portfolio Vol. 24 No. 4, pp. 52- 65.

Ricciardi and Simon (2008), "The Psychology of Risk: The Behavioral Finance Perspective", in Fabozzi, F.J. (Ed.), Handbook of Finance: Volume 2: Investment Management and Finance Management, John Wiley \& Sons, Inc.

Sadi, R., Asl, H.G., Rostami, M.R., Gholipour, A. and Gholipour, F. (2011), "Behavioral Finance: The Explanation of Investors' Personality and Perceptual Biases Effects on Financial Decisions", International Journal of Economics and Finance, Vol. 3, No. 5, pp. 234-241.

Sahi, S.K. and Arora, A.P. (2011), "Individual Investor Biases: A Segmentation Analysis", Qualitative Research in Financial Markets, Vol. 4 No. 1, pp. 6-25. 
Shefrin, H. (2007), Behavioral Corporate Finance: Decisions That Create Value. McGrawHill/Irwin, Boston.

Shefrin, H. and Statman M. (2000),'Behavioral Portfolio Theory", Journal of Financial and Quantitative Analysis, Vol. 35, No. 2, pp. 127-151.

Wolman, B.B. (1973), Dictionary of Behavioral Science, Van Nostrand Reinhold Company. Zacharakis, A. McMullen, J. and Shepherd, D. (2007), "Venture Capitalists' Decision Policies Across Three Countries: An Institutional Theory Perspective", Journal of International Business Studies, Vol. 38 No. 5, p. 691-708. 